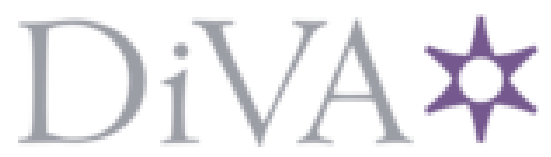

http://www.diva-portal.org

\title{
Postprint
}

This is the accepted version of a paper presented at Cyber Worlds 2014.

Citation for the original published paper:

Hayashi, M., Bachelder, S., Nakajima, M. (2014)

A New Virtual Museum Equipped with Automatic Video Content Generator.

In:

N.B. When citing this work, cite the original published paper.

Permanent link to this version:

http://urn.kb.se/resolve?urn=urn:nbn:se:uu:diva-234413 


\section{A New Virtual Museum Equipped with Automatic Video Content Generator}

\author{
Masaki Hayashi \\ Steven Bachelder Masayuki Nakajima \\ Department of Game Design \\ Uppsala University \\ Visby, Sweden \\ masaki.hayashi@speldesign.uu.se
}

\author{
Akihiko Iguchi \\ Astrodesign, Inc. \\ Tokyo, Japan \\ aiguchi@astrodesign.co.jp
}

\begin{abstract}
Virtual Museum service has been carried out in many places owing to the advanced video and network technology in recent years. In the virtual museum, people primarily experience the prepared content actively with a mouse, a touch panel and specially designed tangible devices. On the other hand, in a real museum space, people appreciate the artifacts passively walking around the space freely without stress. It can be said that the virtual museum is designed to urge people to deal with it rather actively when compared to the real museum.
\end{abstract}

We have been studying and developing a new type of virtual museum enabling people to participate the space with both active and passive way, by implementing various new functions. In this time, we developed the new virtual museum equipped with a video content generator using the virtual exhibition space modeled with 3D computer graphics (CG). This video content is created in real-time by using the 3DCG-modeled museum space as it is, adding appropriate visual and audio effects such as camerawork, superimposing text, synthesized voice narration, back ground music etc. Since this system is working in the 3DCG space, a user can easily go back and forth between the two modes of watching the video content passively and doing walkthrough in the space actively by a wheel mouse.

In this paper, we first introduce primary virtual museums in the world. Then, we describe our method: 1) specially designed walkthrough algorithm, 2) the video content generator using the 3DCG museum space and 3) seamless integration of the 1) and the 2). We then describe our functioning prototype followed by the conclusion and the future plans.

Keywords- Virtual museum; Video content; Walkthrough; Real-time CG; TVML; $4 \mathrm{~K}$

\section{INTRODUCTION}

Museum is one of the primary cultural facilities which are spread widely in the country. In the long history of museum, a special form of exhibition with full use of technology such as video engineering, database and multimedia etc., has been adopted with the background of rapid advances in technology around the late 1980s. In recent years, we can see that the Virtual Museum has been developed in a variety of forms in addition to the real museum by the maturation of the network environment which is based on the
Internet and the imaging technology such as computer graphics (CG).

Virtual museum also has a wide variety of contents. There are many types of presentation content, from what you simply see on the monitor to select the artifacts of the museum, all the way to what you can browse the related detailed information of the artifacts in the interactive ways. Whether on the monitor set in the museum space or on the individual terminal, a user needs to operate the user interface such as a dedicated touch panel or a mouse to experience the provided contents. Therefore, almost nothing may happen unless the user actively interacts with it. Most of the content provided by virtual museum is based on the interactive action basis. On the other hand, the relationship of visitors and the artifacts displayed in the real museum, is rather passive. The visitor appreciates the artifacts while hanging around in the space without feeling stress, seeing the works from a distance and from time to time closely approaching the works to observe intensely. The situation is mostly passive and the stress is a minimum. As described above, the virtual museum is dominated by active action of the user, when compared to the real museum.

We have been studying and developing a system with functions capable of both active and passive ways of user experience, by implementing more passive elements to the virtual museum. This time, we propose a new virtual museum equipped with a video content generator. The museum itself is primarily made using 3DCG where a user can walkthrough. And the user can watch the video content made by the generator using the same CG models. Thus, this is not a pre-recorded video like the one in the real museum, although it tries to simulate a real monitor playing video content set in the real space. The video content of our system is generated in real-time using $3 \mathrm{D}$ models of the virtual museum, by adding camerawork, superimposing text, narration, background music (BGM) etc. Furthermore, the system enables a user to make a transition seamlessly and instantly between the walkthrough and the video content.

In this paper, we first survey the major virtual museums that have been done in the world, and explain them from the point of view of whether passive or active user experience. Then, we describe our proposed system which seamlessly integrates the walkthrough and the video content presentation. Our special walk-through method, the real-time video generation method using 3D models of the virtual 
museum and seamless transition between the walkthrough and the video viewing, are explained. Next, we describe the technical details of the developed system and introduce the results of the system with discussion, followed by the conclusion and the future plans.

\section{EXISTING VIRTUAL MUSEUMS}

In this chapter, we introduce some existing virtual museums primarily from the viewpoint of whether active or passive way of user appreciation in the museum.

Various exhibition auxiliary systems have been done in the real space of the museum for a long time [1]-[7]. Those are, for example, to playback video contents on a monitor set up in the exhibition space, to assist a user to search and browse the museum collection by dedicated software installed in a computer set up in the museum, to provide a visitor the tools with which the visitor can operate by pressing the buttons, etc. helping people to understand the exhibition. In addition, in terms of using for voice, many museums offer "Audio Guide" service. With a given audio guide machine with earphone, a visitor can hear the commentaries while watching the artifacts of the exhibition. In recent years, from advances in digital technology, the monitor becomes larger size and high-definition, sometimes equipped with a touch panel for interactive use (see Fig. 1). In addition, some museums lend a Pad to a visitor to carry on and the visitor is able to get the related information not only by audio but also visually.

Those auxiliary exhibition forms can be said to be the tools for a hands-on exhibit with which a visitor operates the touch panel, the buttons or the tangible devices actively. A few exceptions may be the audio guide and the video content display which correspond to the passive experience, when viewed in terms of passive type of exhibition.

On the other hand, there are also many virtual museums available on the Web. Most of the museum in the world has a home page providing the related information in various forms over the Internet. The world's largest service of virtual exhibition may be the "Google Art Project" provided by Google (Fig. 2) [8]. Google has partnered with many museums around the world, to have virtual exhibitions on the sites using materials provided from the museums. As shown in Fig. 2-A, they first film the real museum space with the same technique used in Google Street View, and provide the panorama image with which a user can look around and walk through the space 360-degree freely with a user interface similar to Street View. When a user chooses an art work while doing walkthrough, she or he changes the mode by clicking an icon appearing near the art work to further

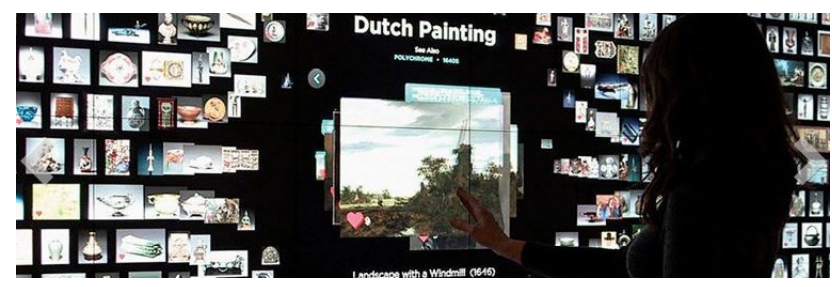

Figure 1. Video wall with touch sensor (Cleveland Museum)

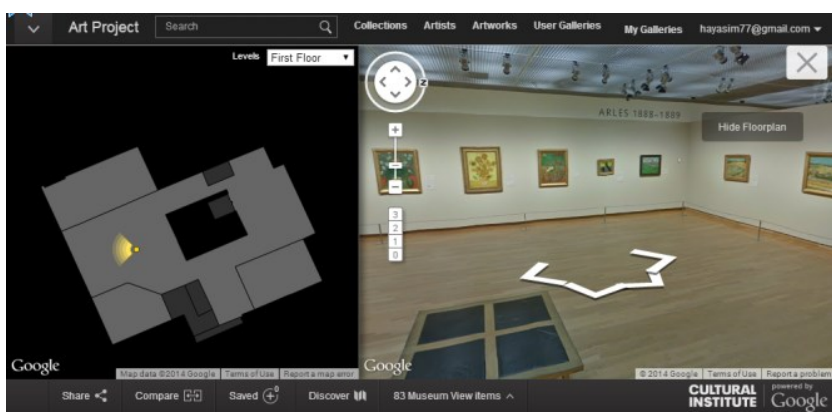

(A) Walkthrough mode

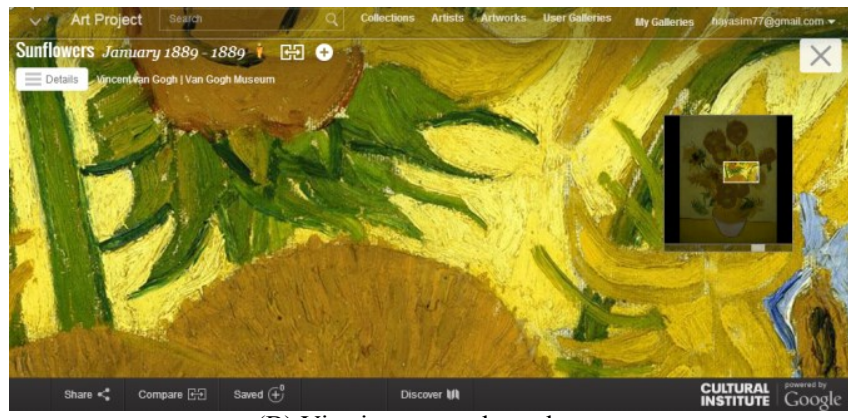

(B) Viewing art work mode

Figure 2. Google Art Project (Van Gogh Museum)

observe it (Fig. 2-B). In this mode, the user can scroll and scale the digitized two-dimensional image of the art work by operating a mouse. The service provides a relatively passive way of walkthrough and scrolling and scaling the art work, and as well as an interactive way to draw the related information by clicking numerous hyperlinks.

The Google Art Project is a very useful service offering the information of the museum from various points. However, it would be difficult to use it with full functions unless the user gets involved in it actively because the variety of the information is much diverse in a deep hierarchical information structure.

From the discussion above, we can conclude the following. Compared to real museum, the mainstream of virtual museum is designed for active type of content and service. They are not very good at making a user to enjoy it in a very relaxed passive manner.

Thinking about this point, we have been seeking a new form of virtual museum with a capability of providing content in a relaxed and passive way that one can only experience in a real museum. This time, we propose a new virtual museum and develop the functioning system which accommodates video content generation with 3DCG museum space. We will describe it in the next chapter.

\section{WALKTHROUGH AND VIDEO CONTENT GENERATOR}

We have already developed a system by modeling the entire exhibition with high-resolution $3 \mathrm{DCG}$, to display the real-time $\mathrm{CG}$ on a $4 \mathrm{~K}$ high-resolution monitor [9]. This time, we use the same system where we add a function to generate video content in real-time. With this system, the walkthrough mode where a user can walk around the 3D museum space 


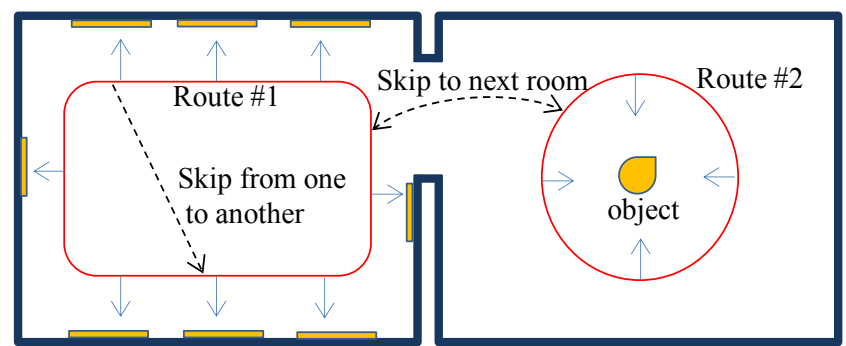

Room \#1 with paintings

Room \#2 with a 3D object

Figure 3. Pre-defined regular route (indicated in red, top view)

and the video viewing mode where a user can watch the video content regarding the artifact, are allowed to come and go seamlessly at any time.

In the subsequent sub-chapters, we will describe the walkthrough algorithm in the walkthrough mode, the video content generating method in the video viewing mode and the method of seamless connection of the two different modes.

\section{A. Walkthrough Mode}

For the walkthrough of 3DCG space, we can use a common approach of First Person Camera in game. In most cases, this is a method to move forward or backward in the direction which is controlled by using a mouse, a keyboard or a joystick. This walkthrough method works well for First Person Shooting game, however, it is not a very good way to appreciate art works such as planar paintings and threedimensional objects put on the exhibition space. It is not easy to design the appropriate walkthrough for virtual museum because the walkthrough in 3D space has too much degree of freedom. Therefore, the method of switching mode between walkthrough and observing an individual artifact, is used for most of the existing virtual museums explained in the Chapter 2. For the specific use for museum, we design a special walk-through method. With this method, we can achieve a seamless transition of walkthrough and observing individual artifact without mode switching.

First, a regular route used for touring the museum room is defined in advance as shown in Fig. 3. Fig. 4 shows the mechanism of the walkthrough algorithm as in this case that the wall is decorated with planar art works such as paintings. The camera (view point of a user) goes forward or backward along with the pre-defined route by moving the mouse horizontally. Direction of the camera keeps on facing to the art works. It makes it possible to look through all the art works in the exhibition space just with the one-dimensional motion. In addition, with respect to a point on the route, a user can get closer or further away the art work by rotating the mouse wheel, and change the height of the camera by moving the mouse vertically. And the direction of the camera in the current camera position can be changed by moving the mouse with holding the left mouse button. The camera moves toward the direction of the view by rotating the mouse wheel. It is thereby possible to move in the 3D space at your will freely as with the normal walkthrough.

In addition, it has a function of skipping the route. As shown in Fig. 3, if the camera falls out of the route and approaches to another art work by using the mouse wheel, and when it gets close enough to the art work, then the skip occurs from the previous position to the new position on the route. By this method, a user does not necessarily see the art works in the order of the route. You can walk through the space then skip the route to see the favorite piece of work.

In the case of a solid $3 \mathrm{D}$ object such as sculpture, the regular route is defined around the subject as shown in the right room in Fig 3. Unlike the case of flat picture, the camera direction is made to face the object inside, as in the Figure. Operation of the mouse and the wheel and pressing the left button works in the same way as described above. Thus, it is possible to travel around the 3D object getting closer to or further away freely.

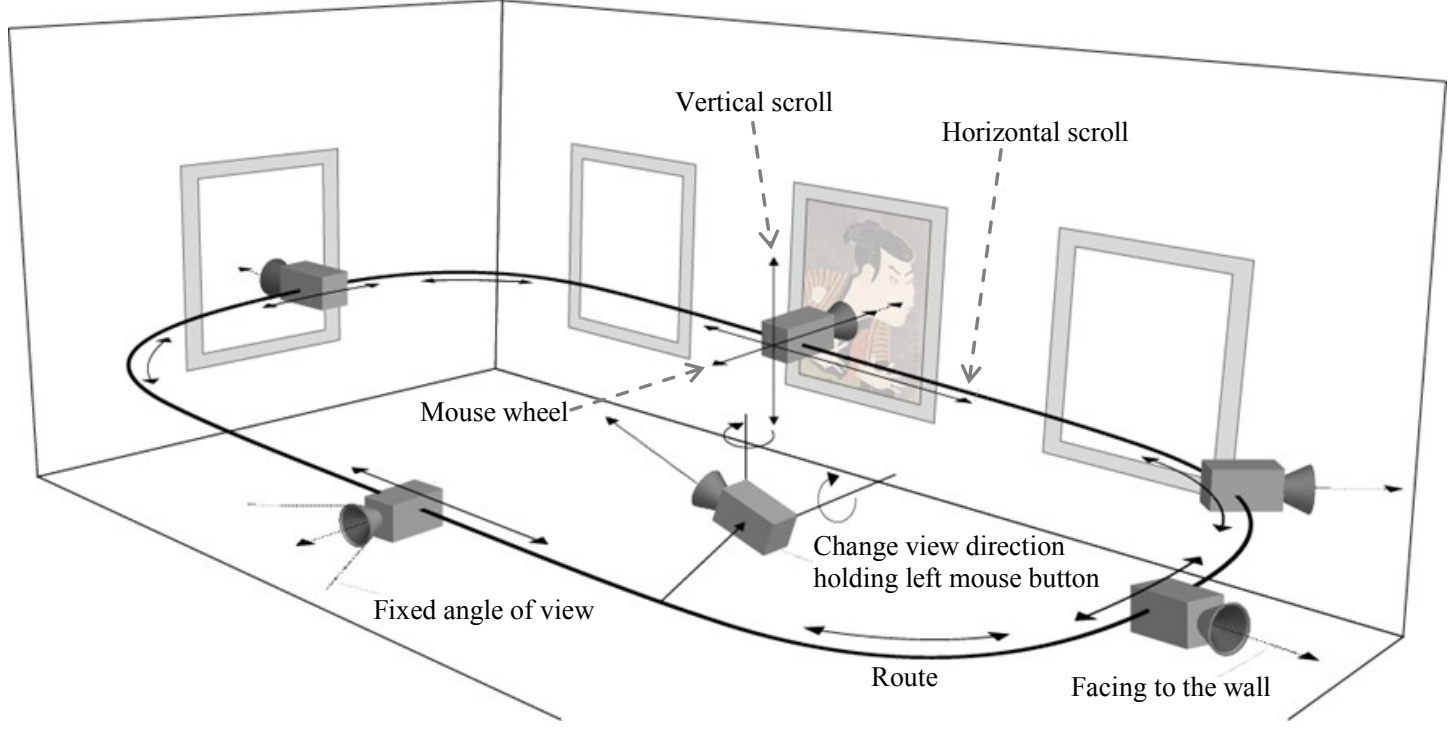

Figure 4. Walkthrough algorithm 
Furthermore, in order to make it possible to use multiple rooms, it has a function of skipping from a route to another route. As shown in Fig 3, the routes for each room are defined and it can come and go through the doorway skipping the routes. A user operates the mouse wheel to go towards the exit (entrance of the next room), by detecting that it has passed through the exit, then the user is automatically taken to the new route of the next room.

By this algorithm described above, we successfully enable a user both walk along the regular route to appreciate the art works without stress and observe the details of an individual art work in a natural way as possible.

\section{B. Video Content Generator}

In a television show regarding art, one can see a show format with the art works filmed by a TV camera with camerawork, narration, superimposing, sound effect and BGM etc. The content is an explanatory commentary of the works and the artists. Sometimes, materials other than the pictures of art works, such as photos of the artists, history of the home country of the artists etc. are inserted to the video content. In addition, a scene where an announcer and a commentator talk in a talk show setup in a studio or a scene where they actually walk in the museum space to explain the art works, can be inserted sometimes in the TV show.

We have made a system which produces such TV program-like video content using the 3DCG models in the museum space as they are. All the stories, speech lines and the necessary materials for the content production, are prepared in advance. The system produces the TV programlike art show basically by virtual shooting in the 3DCG museum, adding narration, superimposing and BGM etc.

We use TVML (TV program Making Language) technology [10] to create the TV program-like video content using 3DCG in real-time along with the story board. TVML is a special language to describe TV program and a TVML engine generates a TV program by interpreting the TVML script. As shown in Table 1, most of the effects which are necessary for producing TV program are ready to use. TVML engine interprets a TVML script to generate the

Table 1. TV production versus TVML event type

\begin{tabular}{|c|c|c|}
\hline Category & TV production & TVML \\
\hline Studio shot & Studio set & set \\
\cline { 2 - 3 } & Prop & prop \\
\cline { 2 - 3 } & Actor & character \\
\cline { 2 - 3 } & Lighting & light \\
\cline { 2 - 3 } & Camera & camera \\
\hline Footage & Video playback & movie \\
\hline Telop & $\begin{array}{c}\text { Text, image } \\
\text { display }\end{array}$ & title \\
\hline Superimpose & $\begin{array}{c}\text { Text, image } \\
\text { display }\end{array}$ & super \\
\hline Art work & Making figure & drawing \\
\hline Sound & Sound effect & sound \\
\cline { 2 - 3 } & Audio mixing & sound \\
\hline
\end{tabular}

output audio and video.

This TVML engine is integrated to the 3DCG real-time walkthrough system described in the chapter 3-1 to produce the video content. TVML technology includes character animation so that it could create a type of content with a virtual announcer and a commentator. This time, however, we do not use this character animation function. Instead, we use several TVML functions as in the Table 1 such that "character: talk" (narration by synthesized voice), "drawing" (superimposing), "sound" (BGM) and "camera" (virtual shooting in the 3DCG space).

The story board of the video content is prepared in advance for each art work exhibited in the virtual museum. The system plays back the story for one art work, and when it is finished, then it proceeds to the next story of the next art work, showing each story one by one. The playback order complies with the order which has been predefined by the regular route described in the chapter 3-1. Therefore, if you keep on playing the video content, it is automatically to show each and every art works exhibited in the museum.

\section{Seamless Connection}

The system is designed to realize the seamless integration of the walkthrough explained in the 3-1 and the video content generation explained in the 3-2 so that a user can come and go the two different types of mode naturally. Such continuous transition of these two modes can be achieved by having the continuity of the camera since those two functions are implemented on the same platform. In case of the transition from walkthrough to video content, the system detects the target art work that the user is looking at during the walkthrough described in 3-1, then starts playing back the story of the target art work. When the queue is issued, the camera position in the walkthrough is continuously travelled to the first camera position in the story written in TVML to avoid the visual discontinuity. Also, the same visual continuity is done in the case of the transition from video content to walkthrough.

This time, we use keyboard hit for the queue of the transition although any device is available for this. Also, we setup the timeout control to switch from walkthrough then to start the video content playback when a user does not touch the mouse for a certain time. When the user touches the mouse during the playback, the system senses it and switches to walkthrough mode immediately.

\section{TEST System AND DisCUSSION}

\section{A. System Development}

We have developed a functioning test system based on the method described in the chapter 3. The system is basically constructed on the 3DCG game engine "Unity (free version)". The TVML engine which generates TV programlike video content in real-time, is implemented to the Unity project by importing the Unity version of TVML SDK (System Development Kit) [11].

The entire museum comprised of the 3D exhibition space and the artifacts, is modeled by a designer paying attention to its reality. As shown in Fig.5, we prepare three rooms in 


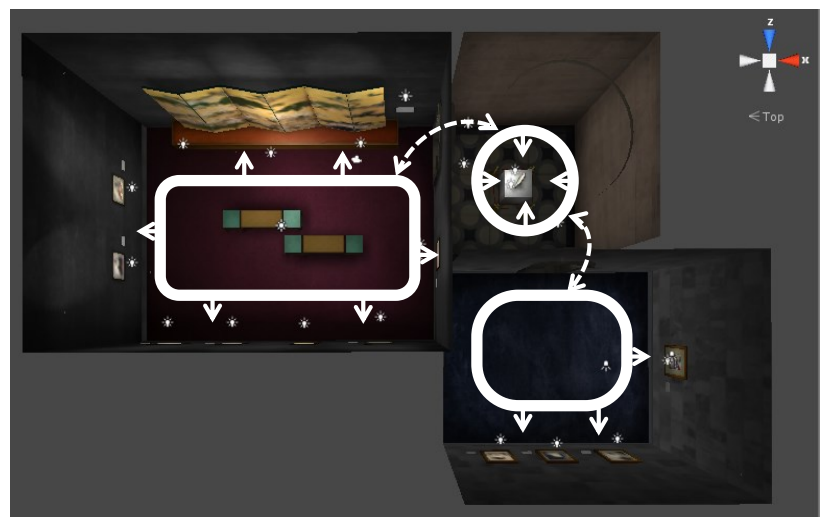

Figure 5. Top view of the museum and the routes

which Japanese wood prints, panels, drawings and 3D objects such as archaeological artifacts etc. are displayed. Those artifacts have been digitized in high-resolution. For example, a Japanese wood print (actual size is approx. $24 \mathrm{x}$ $35 \mathrm{~cm}$ ) has been digitized in a resolution of approx. $6500 \mathrm{x}$ 9500 and is displayed in the 3D space with the texture whose size is $4096 \mathrm{x}$ 4096. This high-resolution digitization enables a user to observe the detailed surface of the artifact in a very close distance.

Fig. 6 shows the architecture of the software. It basically consists of the walkthrough engine and the TVML engine. The walkthrough engine first reads a "route.txt" text file in which pre-defined regular routes are described. Numerous exhibition rooms and numerous routes for the one room can be defined in the "route.txt". The route is defined by

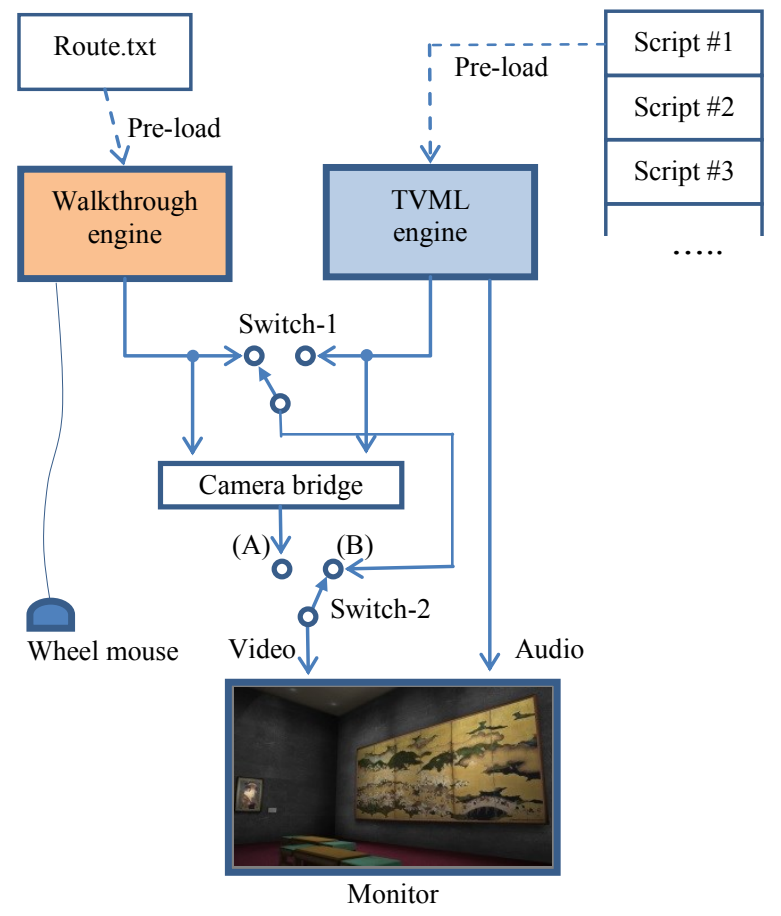

Figure 6. architecture of the software
Quadratic Bezier curve and a list of the control points are written in the "route.txt". The engine calculates the position ( $x, y, z$ - coordinate) and the orientation (rotation angles: rx, ry, rz) of the camera from the values of the mouse based on the algorithm explained in the chapter 3-1. When moving along the route by horizontal movement of the mouse, it maintains a constant linear velocity to simulate the feeling of walking along the route at constant speed as possible.

Each artifact has a corresponding TVML script telling the story about the artifact. TVML engine plays back the script one by one. As explained in the chapter 3-2, the engine shoots the artifact in the 3D space by moving the camera up, down, left and right and in the depth direction (corresponding to horizontal and vertical scroll and zoom) and makes a cut change between the cameras. And the engine adds appropriate narration explaining the artifact, subtitle, superimposing text and BGM to create a TV program-like video content.

As shown in Fig. 6, the system gives the final image after switching those two outputs of the engines. The selector switch "Switch-1" switches the two outputs in the manner explained in the chapter 3-3. In order to avoid the visual discontinuity right after switching, the "Switch-2" switches to (A) to perform a visual function to bridge the two different cameras continuously.

As the hardware, we have constructed the system not only on an ordinary PC but also on a $4 \mathrm{~K}$ ultra-highresolution imaging system. Fig. 8 shows the configuration. The system consists of a PC with a GPU card "FirePro W7000" of AMD and a 4K monitor "TX-L65WT600" of Panasonic. By connecting the card and the monitor by single DisplayPort cable, it can display $4 \mathrm{~K}$ resolution real-time $\mathrm{CG}$.

\section{B. Discussion}

Fig. 8 shows the output images of the system. We conducted a test with the $4 \mathrm{~K}$-resolution system and obtained the following results.

- Our special walkthrough algorithm explained in the chapter 3-1 requires a user to practice a little however, the walkthrough is fairly comfortable after the user gets used to it. However, people who are already familiar with the First-Person-Camera in the game, sometimes feel frustration when it does not let them fly over to the desired position immediately. We should provide an

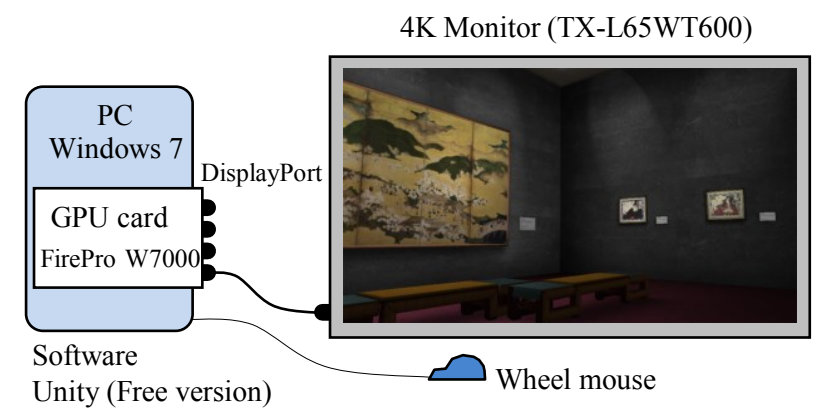

Figure 7. Configuration of $4 \mathrm{~K}$ virtual museum 
option to choose several types of walkthrough algorithms for the different type of users.

- It appears as an unexpected surprise for users to observe the artifact closely in a very high resolution without the mode change which is used in the most of the existing virtual museum described in the chapter 2 . Visual representation on a large $4 \mathrm{~K}$ monitor has been attracting attention of video industry people as a new way of utilizing $4 \mathrm{~K}$ technology.

- The function of real-time generation of the video content is new. It is surely depending on the quality of the content production. And the most important point of this method is how we can produce an attractive TVML script from the content point of view. It could be possible to produce higher grade video content because TVML technology has more functions which have not been used in this time, such as character animation and movie file playback etc.

- However, due to the very high quality modeling of the museum itself, it might not balance unless the quality of the video content is also high. And if the balance is lost, it might be ended up giving a user a bad impression of the whole system. Therefore, we need to care about the quality of the video content so as to maintain sufficient level. One of the reasons that we did not use character animation even though it was available, is that we could not prepare such high grade CG characters and their movements performing in the high grade $3 \mathrm{DCG}$ museum.

- Seamless connection of video content and walkthrough is a completely new feature. It can successfully give the user to enjoy the virtual museum in two completely different ways: 1) to find the desired artifact doing walkthrough then to watch the video content of that, and 2) to watch the video content then by touching the mouse and to see the artifact by walkthrough. Those two modes are always switchable to give the user a freedom in appreciating the artifacts. Analogically to say in terms of real museum, we are able to make it possible to simulate the situation where a user walks around the real museum using an audio guide and hears the commentary while viewing the art works.

\section{CONCLUSION}

In this paper, we first take a look at primary virtual museum activities and analyze them from the point of view of either active or passive way of the appreciation. Then we conclude that the virtual museum more or less requires a user to interact actively when compared to a real museum. From this context, we have been aiming to achieve a new type of virtual museum by introducing passive elements to it. In this time, we introduce the virtual museum which integrates walkthrough and video content display in the seamless

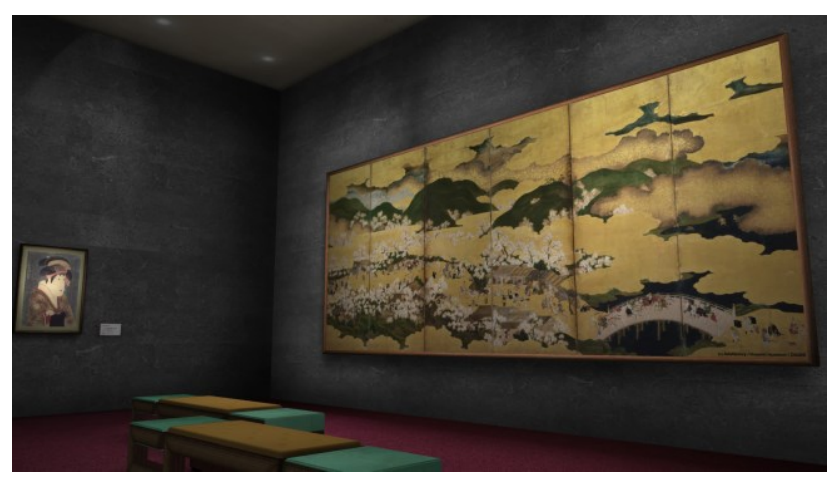

Walkthrough

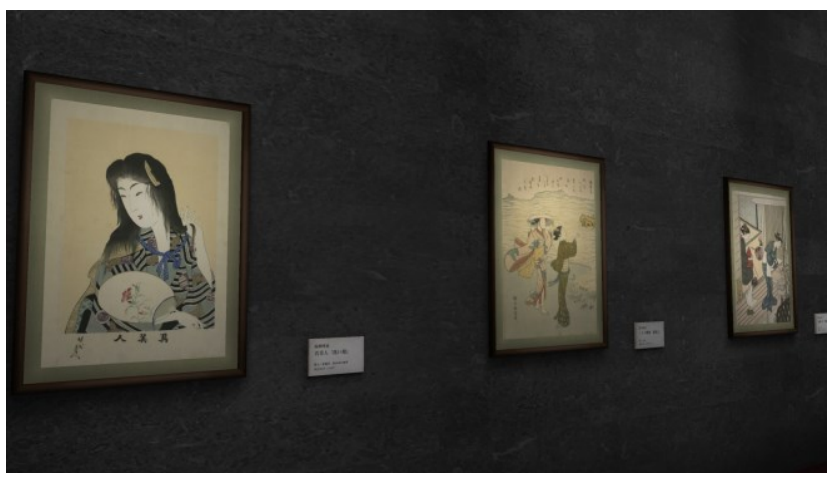

Walkthrough

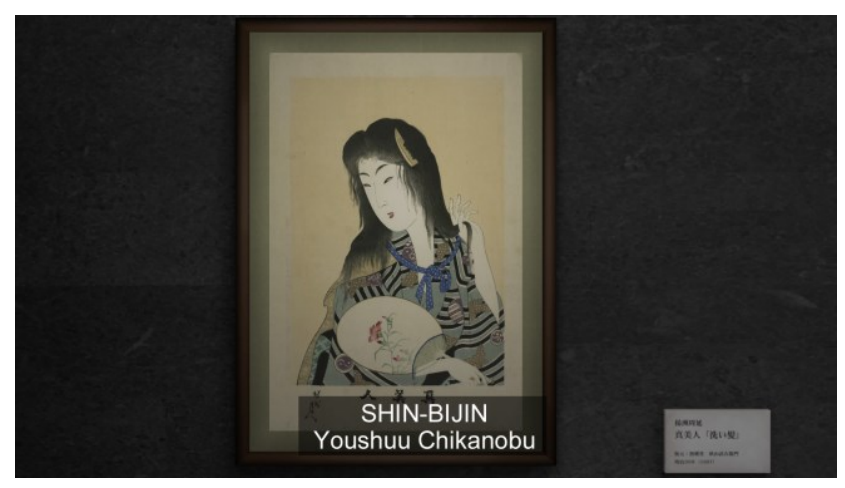

Video content (Superimposing and BGM)

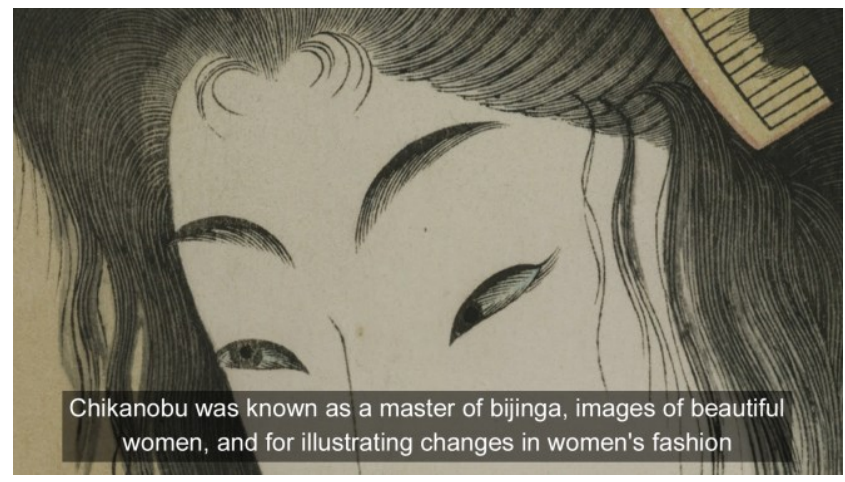

Video content (Narration, subtitle and BGM)

Figure 8. Output of the system 
manner. The video content is generated from 3DCG models of the museum by adding camerawork, narration, superimposing and BGM, etc. The system uses TVML engine to perform those video effects playing back a prepared TVML script. The system is built on the $3 \mathrm{DCG}$ game engine "Unity" by importing the walkthrough algorithm and the TVML playback engine. A user can walk through in the 3D space freely by the mouse and can start watching the video content at any time by hitting a key. The system is designed to avoid the visual unnaturalness at the transition so that a user can come and go these two modes with no stress. By this system, we are able to show one of the solutions enabling the seamless integration of the user behaviors in a museum: to seek an artifact actively in the space and to watch the video content regarding the artifact passively like a television.

We will conduct the research and development on the basis of the discussion made in this paper. The following is our future plans.

- To raise the quality of the video content and to use character animation so that the quality of the video can reach to a higher level comparable to a real TV show.

- Research and development of the operation device to replace the mouse for the walkthrough.

- Introducing interactive contents during the walkthrough. Capability of the real-time interaction with the museum to be able to draw related information by operating graphical user interface.

Our ultimate goal is to create a virtual museum that allows to simulate the situation where one has personally hired a curator, and tour the museum space with the person. The one can walk in the museum freely with no stress, appreciating the artifacts, asking questions to the curator, hearing the commentaries, knowing the history and the background of the artifacts and more. We aim to realize the virtual museum to fulfill such concept.

\section{ACKNOWLEDGMENT}

\section{REFERENCES}

[1] Toppan Virtual Reality: http://www.toppanvr.jp/bunka/en/index.shtml (May 2014 visited)

[2] LOUVRE-DNP Museum Lab : http://www.museumlab.eu/ (May 2014 visited)

[3] The Cleveland Museum of Art: http://www.clevelandart.org/ (May 2014 visited)

[4] Louvre Online Tours: http://www.louvre.fr/en/visites-en-ligne (May 2014 visited)

[5] e-Museum, National Institutes for Cultural Heritage: http://www.emuseum.jp/top?d_lang=en (May 2014 visited)

[6] 3D-GALLERY, GRAPHTWERK: http://3dstellwerk.com/en/ (May 2014 visited)

[7] Galerie Bel'Art - Stockholm: http://www.belart.se/3dgallery/introduction/ (May 2014 visited)

[8] Google Art Project: http://www.googleartproject.com/ (May 2014 visited)

[9] M. Hayashi, M. Nakajima, S. Bachelder, A. Iguchi, S. Machida: "Ultra High Resolution 4K/8K Real-time CG System and Its Application", Proceedings of IWAIT2013, Jan. 7-9, (2013)

[10] M. Hayashi, S. Inoue, M. Douke, N. Hamaguchi, H. Kaneko, S. Bachelder, M. Nakajima: "T2V: New Technology of Converting Text to CG Animation", ITE Transactions on Media Technology and Applications, Vol.2, No.1, pp.74-82 (2014)

[11] M. Hayashi, S. Bachelder, M. Nakajima, T.Nigorikawa: "System Development Kit of T2V in the Unity - T2V Engine Capable of Converting Script to CG Animation in the Unity Game Engine-", Proceedings of Art and Science Forum, (2014) 